\title{
Urinary Bladder Neoplastic Masses Findings through Multidetector-Row CT Urography
}

\author{
OLA H. ABDUL AL AMEER, M.Sc.; SAHAR M. EL GAAFARY, M.D. and ALI H.A. NOOR AL DEEN, M.D.
}

The Department of Radiodiagnosis, Faculty of Medicine, Ain Shams University

\begin{abstract}
Background: Urinary bladder carcinoma is one of the most common tumors among the lower urinary tract, it is the seventh common malignancy and widely distributed in developed countries.
\end{abstract}

Aim of Study: To elucidate the diagnostic potential and additive imaging data obtained with Multi-Detector Computed Tomography (MDCT) in early detection and characterization of urinary bladder neoplastic masses by comparing the result of the study with the conventional cystoscopy results.

Patients and Methods: This prospective descriptive study was conducted on forty patients, 36 was men and 4 women. The patients referred to Radio-Diagnosis Department, Ain Shams University Hospitals, Radio-Diagnosis Department in a period 6 months of data collection for suspicious bladder mass(es) after clinical assessment of patient or for further characterization of indeterminate bladder neoplastic mass lesion previously depicted on other radiological investigation as ultrasound examination.

Results: A statistically significant difference was found between positive and negative cystoscopic biopsy results for malignancy in relation to presence $\mathrm{CT}$ features of malignancy.

Conclusion: MDCT urography is useful for examination of patients especially when the $\mathrm{CC}$ is contraindicated such as hemorrhage, perforation, difficult to doing it or unsatisfactory in interpretation, and as a complementary technique in the evaluation of areas difficult to evaluate with $\mathrm{CC}$, especially with the MDCT results satisfactory in finding lesions smaller than $5 \mathrm{~mm}$. MDCT urography gives us an opportunity for early detection bladder tumors because its reliability and accuracy and our results support that.

Key Words: Urinary bladder neoplasm - Multidetector-row CT urography.

\section{Introduction}

PATHOLOGIC conditions of the urinary bladder could manifest as a focal mass or diffuse urothelial wall thickening. Focal masses might be neoplastic

Correspondence to: Dr. Ola H. Abdul Al Ameer, The Department of Radiodiagnosis, Faculty of Medicine, Ain Shams University or could develop sequent to congenital, inflammatory, idiopathic, or infectious processes. Clinical, macroscopic, and radiologic findings for these masses may superimpose; therefore, histologic interrogation is often a necessity [1]. Benign mass lesions are uncommon; however, some can be suggested by their imaging criteria [2] .

Urinary bladder carcinoma is a heterogeneous disease with a variety of pathologic features, cytogenetic characteristics, and natural histories whereas the most common clinical presentation is gross painless hematuria [3]. In Egypt, urinary bladder carcinoma is the most prevalent malignancy among Egyptian males (19\%), giving rise to $15.6 \%$ of cancer-related deaths that formerly has been assigned to Schistosoma infection, a considerable risk factor for Squamous Cell Carcinoma (SCC). Latterly, Transitional Cell Carcinoma (TCC) incidence has been rising up as a sequence of heavy cigarette smoking, occupational exposures to carcinogens, while SCC has lessened [4]. In Egyptian females, UB carcinoma is the seventh common malignancy $(3.8 \%)$, bringing about $3.7 \%$ of cancerrelated deaths [5].

Early depiction of UB carcinoma is of paramount importance, since up to $47 \%$ of UB cancerrelated mortalities may have been averted [6] Precise pre-operative staging is the most important element in delineating the appropriate management of UB carcinoma in view of fact that the therapeutic strategy selected and prognosis rely on the clinical and radiological stage at presentation [7]. Moreover, UB carcinoma has a high recurrence rate, necessitating long-term surveillance following initial therapy $[8]$.

Conventional cystoscopy is the mainstay of diagnosis and follow-up of UB neoplasia [9]. None- 
theless, it's famed as an invasive, expensive, timeconsuming technique, coupled with urinary tract infections in 5-15\% of patients. Another drawback of cystoscopy is the relatively low reported sensitivity of $87 \%$ for detection of UB tumors [10].

Clinical staging of UB carcinoma based upon bimanual assessment of tumor bulk and adhesion to nearby structures proved to be imprecise, with an inaccuracy rate of $25 \%-50 \%$. Thus, accurate detection and staging are the principal objectives of radiologists in evaluation of patients with UB cancer [11].

Computed Tomography (CT) and Magnetic Resonance (MR) imaging are the principal radiologic modalities utilized in assessment of patients with UB cancer. The inherent advantages of CT encompass shorter acquisition time, wider coverage in a single breath hold adding to multiplanar capability. Contrariwise, CT is limited in the characterization of small and early stages of UB cancers, whilst its staging accuracy ranges from $64 \%$ to $92 \%$. Furthermore, the enhancement pattern of UB carcinoma regarding peak enhancement time and degree of enhancement on contrast materialenhanced CT images has not been analyzed. It is known, however, that bladder cancers usually enhance more intensely than nearby normal UB wall tissue [11].

In the last decades; recent advances in CT hardware coupled with commercially available software had led to the development of the multidetector row helical CT scanner, which could provide higher resolution and more compact volume acquisition in a shorter time with anticipated improvement in evaluation of patients with UB carcinoma [11]

\section{Aim of the study:}

The aim of this study is to elucidate the diagnostic potential and additive imaging data obtained with Multi-Detector Computed Tomography (MDCT) in early detection and characterization of urinary bladder neoplastic masses by comparing the result of the study with the conventional cystoscopy results.

\section{Patients and Methods}

This is a prospective descriptive study where the data collected from Ain Shams University Hospitals, Radio-Diagnosis Department in a period 6 months of data collection (10/2018 to 4/2019). In our study the patients were (40 patients), 36 was men and 4 women patient age range [mean \pm SD] 35-78 [62.48 \pm 9.13$]$. The patients referred to
Radio-Diagnosis Department-Body Imaging Unit to perform pelvic CT either for suspicious bladder mass(es) after clinical assessment of patient or for further characterization of indeterminate bladder neoplastic mass lesion previously depicted on other radiological investigation as ultrasound examination.

\section{Inclusion criteria:}

- The criteria for selecting a patient in the current study was presence of: Patients have a bladder mass(es) suspected clinically after a digital rectal examination in men or on a vaginal examination in women, and/or radiologically by Pelviabdominal ultrasonography, or a history of bladder carcinoma.

- Both sexes were included.

- No age predilection.

\section{Exclusion criteria:}

- Hypersensitivity to iodinated contrast media.

- Poor renal function (Creatinine $>2 \mathrm{mg} / \mathrm{dl}$ ).

- Contraindication to ionizing radiation.

All patients were subjected to:

- Full history taking for each patient, including:

- Onset, course, and duration of the main complaint.

- History of the present illness.

- Past history of bilharzial infection and occupation.

- General and local examinations.

- Laboratory studies including urine analysis, complete blood picture, renal function tests, liver profile.

- Radiological and imaging investigations include:

- Plain urinary tract film.

- Intravenous urography.

- Real time abdominal ultrasound.

- CT scanning of the Abdomen and Pelvis.

Ethical considerations: Detailed explanation of the imaging procedure and obtaining informed consent. The consent were contain:

- Explanation of the study aim in a simple manner to be understood by common people.

- No harmful manoeuvres were performed or used.

- All data was considered confidential and it has not gone to be used outside this study without patient's approval. 
-All samples were used in the research only.

- Researcher phone number and all possible communicating methods were identified to the participants to return at any time for any explanation.

- All participants were announced by the result of the study.

- Participants have the right to withdraw from the study at any time without giving any reason and shall be excluded from the study.

- Signature or fingerprints of the participants.

Risks and complications: Multi-detector CT scan is considered to be a safe procedure; but if occurred, the possible complications were:

- Anaphylactoid reaction to contrast media.

- Headache and nausea.

- Deterioration/elevation of serum kidney function.

Treatment in cases of risks and complications:

- Bed rest following the procedure.

- Adequate hydration.

- Premedication with steroid, Diphenhydramine $10 \mathrm{mg}$ iv,. Epinephrine $(1: 1,000) 0.5 \mathrm{ml}$ subcutaneously if no cardiac contraindications in the acute incident in cases of allergic reactions.

Study tools:

Each patient was undergoing the following:

- Proper history taking encompassing: Personal data (name, age, sex, occupation, address and special habits) and clinical data (pubic pain, hematuria, dysuria, fever).

- Full clinical and laboratory assessment of the relevant data.

- Dynamic contrast enhanced multiphasic CT images were acquired after full distention of the bladder.

Results of MDCT pelviabdominal study were compared with those of conventional cystoscopy with a flexible/rigid cystoscope done previously in less than 1 week.

\section{Patient preparation:}

- Pre-procedural assessment of renal function including of blood urea \& serum creatinine.

- Administration of an ante-cubital intravenous catheter.

- Patients are instructed not to void for at least 2 hours before the examination.
- Oral administration of 1 litre of water as a contrast agent of which $400 \mathrm{ml}$ is to be drunk immediately before going to scanner.

- Un co-operative patients were given oral sedation in the form of trichlorfon in the dose of $50 \mathrm{mg} / \mathrm{kg}$.

Patient position: Patient is positioned supine on the CT table.

\section{Method:}

- All examinations were done on 80-slice spiral CT scanner (Bright-Speed 80; GE Medical Systems) with a helical thickness of $0.625 \mathrm{~mm}$, and the following parameters: $50 \mathrm{mAs}, 120 \mathrm{kV}$.

- Non-enhanced CT scan of pelvis is obtained.

- FOV should be individualized in each patient to allow complete evaluation of the pelvis, with visualization of the bladder and extra-vesical structures (mean FOV 30 X 40 X 40cm).

- A dose that ranged from a minimum of $2 \mathrm{ml} / \mathrm{kg}$ to a maximum of $160 \mathrm{~mL} / \mathrm{kg}$ of non-ionic intravenous contrast.

- Thereafter dynamic contrast-enhanced multiphasic CT images of the pelvis is obtained with scanning delays of 40, 80, and 180 seconds.

- Post-processing and image analysis data sets obtained were transferred in real time to an advantage workstation and for each scan; MPR should utilized in the sagittal and coronal planes.

- Each examination were analyzed in a blind fashion by a single radiologist with 5 years' experience in body imaging who is unaware of patients' clinical data.

- For each step, a diagnostic judgment was expressed on any lesion identified based on the following parameters: Lesion site (bladder dome, walls, and trigone), size, number and morphology as shall as enhancement pattern. The lesions were described as sessile (broad base tumors), polyploidy (resembling a polyp in shape), or areas of wall thickening. A lesion would be characterized as sessile when it is connected by a broad base to the bladder wall. If it is connected by a narrow stalk, and projecting into the bladder cavity, then it defined as a polypoid lesion. An area of wall thickening were defined when there is no associated distinct masses.

- Bladder lumen and mucosa were studied with a pulmonary window-level setting (1,400/-650 $\mathrm{HU}$; bladder walls and extra-luminal structures had been studied with an abdominal-level setting (420/45HU). 
- Findings detected by CT were compared to the results of histopathological obtained by cystoscopic biopsies.

Statistical package: Recorded data were analyzed using the statistical package for social sciences, Version 20.0 (SPSS Inc., Chicago, Illinois, USA). Quantitative data were expressed as meant Standard Deviation (SD). Qualitative data were expressed as frequency and percentage.

The following tests were done:

- Chi-square $\left(\mathrm{X}^{2}\right)$ test of significance was used in order to compare proportions between qualitative parameters.

- Evaluation of Diagnostic Performance by Receiver operating characteristic (ROC curve) analysis was: Sensitivity, Specificity, PPV, NPV, Accuracy.

- The confidence interval was set to $95 \%$ and the margin of error accepted was set to $5 \%$. So, the $p$-value was considered significant as the following.

\section{Results}

Table (1): CT results distribution of the study group regarding malignant features.

\begin{tabular}{lcc}
\hline CT results & No. & $\%$ \\
\hline Negative & 11 & 27.5 \\
Positive & 29 & 72.5 \\
\hline
\end{tabular}

This table shows that $(72.5 \%)$ were positive malignant feature on $\mathrm{CT}$ and $(27.5 \%)$ were negative for malignant features on $\mathrm{CT}$ results.

Table (2): CT finding distribution of the study group.

\begin{tabular}{lll}
\hline CT findings & No. & $\%$ \\
\hline Mass present or absent: & & \\
Absent & 16 & 40.0 \\
Present & 24 & 60.0 \\
Number of mass $(n=24):$ & & \\
1.00 & 13 & 54.2 \\
2.00 & 5 & 20.8 \\
4.00 & 1 & 4.2 \\
5.00 & 5 & 20.8 \\
Morphology: & & \\
Irregular wall thickening & 13 & 32.5 \\
Polypoid & 18 & 45.0 \\
Sessile & 9 & 22.5 \\
Location: & & \\
Basal & 9 & 22.5 \\
Dome & 14 & 35.0 \\
Lt lateral & 10 & 25.0 \\
Rt lateral & 7 & 17.5 \\
Size (mm): & & \\
<5mm & 15 & 37.5 \\
6-10mm & 12 & 30.0 \\
>10mm & 13 & 32.5 \\
\hline
\end{tabular}

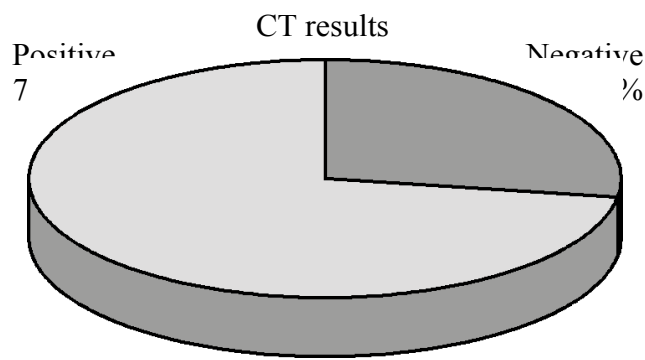

Fig. (1): Pie chart CT results distribution of the study group regarding malignant features.

This table shows that: (60\%) show mass lesion on $\mathrm{CT},(32.5 \%)$ show irregular wall thickening lesion, $(45 \%)$ show polypoid lesion, $(22.5 \%)$ show sessile lesion. As regarding the site (3 5\%) were dome lesion, $(25 \%)$ were Lt lateral lesion, $(22.5 \%)$ were basal lesion and (17.5\%) were Rt lateral of lesions. As regarding the size $(37.5 \%)$ were $<5 \mathrm{~mm}$, $(30.0 \%)$ were $6-10 \mathrm{~mm}$ and $(32.5 \%)>10 \mathrm{~mm}$.

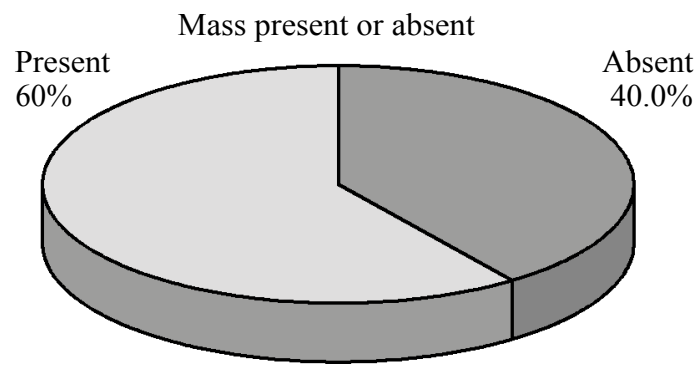

Fig. (2): Pie chart of the study group regarding of the presence of mass onCT.

Table (3): Comparison between positive and negative cystoscopic biopsies results for malignancy in relation to clinical data.

\begin{tabular}{|c|c|c|c|}
\hline \multirow{4}{*}{ Parameters } & \multicolumn{2}{|c|}{ Cystoscopy biopsies } & \multirow{2}{*}{$\begin{array}{c}\text { Chi-square } \\
\text { test }\end{array}$} \\
\hline & \multirow{2}{*}{$\begin{array}{l}\text { Positive } \\
(\mathrm{n}=40)\end{array}$} & \multirow{2}{*}{$\begin{array}{c}\text { Negative } \\
(\mathrm{n}=10)\end{array}$} & \\
\hline & & & $p$-value \\
\hline & No. $\%$ & No. $\%$ & \\
\hline
\end{tabular}

Clinical presentation

by hematuria:

$\begin{array}{lllllll}\text { Negative } & 2 & 6.7 & 1 & 10.0 & 0.120 & 0.729 \\ \text { Positive } & 28 & 93.3 & 9 & 90.0 & & \end{array}$

DRE for male or PV for

female:

$\begin{array}{lrrrrrr}\text { Negative } & 20 & 66.7 & 9 & 90.0 & 2.048 & 0.152 \\ \text { Positive } & 10 & 33.3 & 1 & 10.0 & & \end{array}$

History of urinary

bladder CA:

$\begin{array}{lllllll}\text { Negative } & 23 & 76.7 & 6 & 60.0 & 1.045 & 0.307 \\ \text { Positive } & 7 & 23.3 & 4 & 40.0 & & \end{array}$

Using: $\mathrm{X}^{2}$ : Chi-square test; $p$-value $>0.05$ NS. 


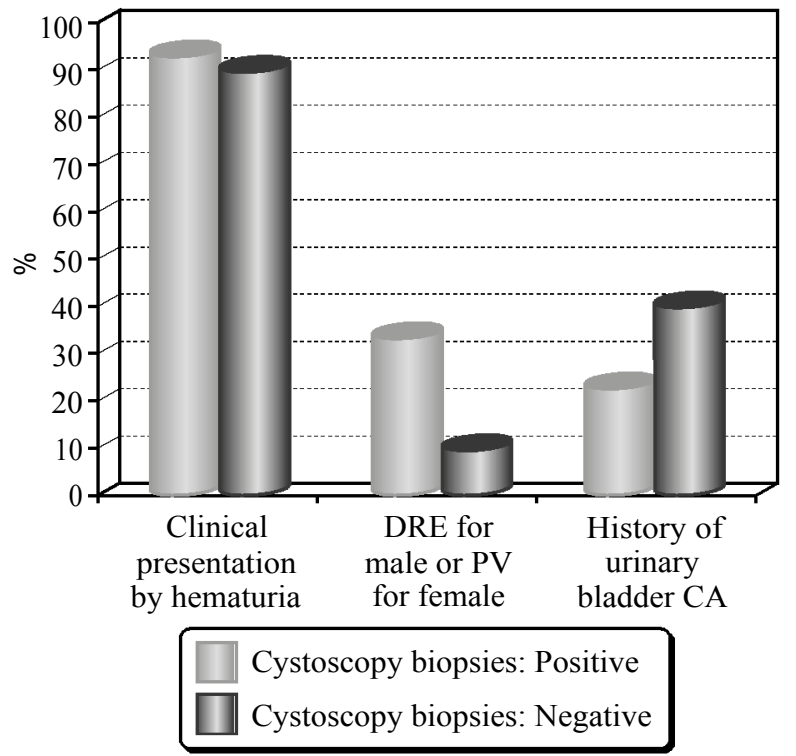

Fig. (3): Bar chart distribution between positive and negative according to cystoscopic biopsies results for malignant cells in relation to clinical data.

Table (4): Comparison between positive and negative according cystoscopic biopsies results for malignancy in relation to CT results.

\begin{tabular}{|c|c|c|c|c|c|c|}
\hline \multirow{4}{*}{$\begin{array}{l}\mathrm{CT} \\
\text { results }\end{array}$} & \multicolumn{4}{|c|}{ Cystoscopy biopsies } & & \\
\hline & \multirow{2}{*}{\multicolumn{2}{|c|}{$\begin{array}{l}\text { Positive } \\
(\mathrm{n}=30)\end{array}$}} & \multirow{2}{*}{\multicolumn{2}{|c|}{$\begin{array}{l}\text { Negative } \\
(\mathrm{n}=10)\end{array}$}} & \multicolumn{2}{|c|}{ Chi-square test } \\
\hline & & & & & \multirow[t]{2}{*}{$x^{2}$} & \multirow[t]{2}{*}{$p$-value } \\
\hline & No. & $\%$ & No. & $\%$ & & \\
\hline Positive & 28 & 70 & 1 & 2.5 & 26.123 & $<0.001 * *$ \\
\hline Negative & 2 & 5 & 9 & 22.5 & & \\
\hline
\end{tabular}

Using: $\mathrm{X}^{2}:$ Chi-square test.

$* * p$-value $<0.001 \mathrm{HS}$.

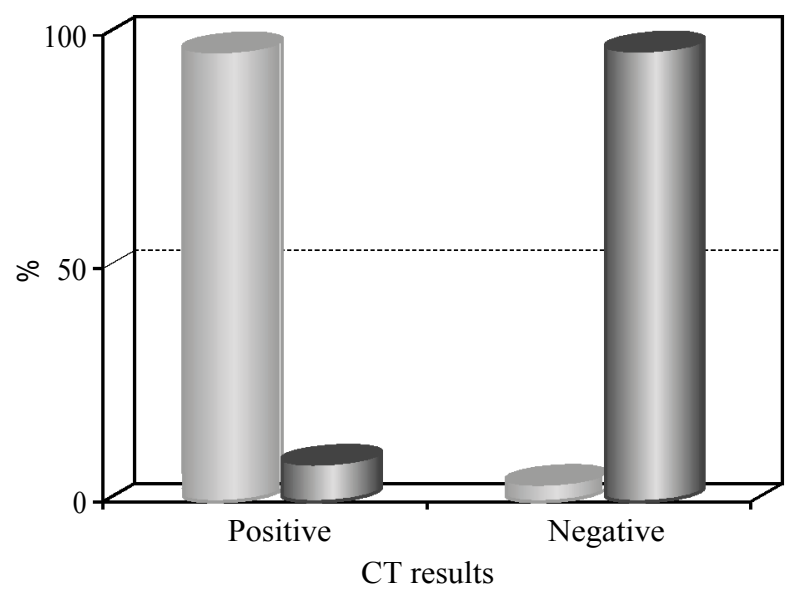

Cystoscopy biopsies: Positive

Cystoscopy biopsies: Negative

Fig. (4): Bar chart distribution between positive and negative cystoscopic biopsies results for malignant cells in relation to $\mathrm{CT}$ result for malignant features.
Table (5): Comparison between positive and negative according cystoscopic biopsies results for malignancy in relation to CT features for the mass.

\begin{tabular}{|c|c|c|c|}
\hline \multirow{3}{*}{$\begin{array}{l}\text { CT } \\
\text { findings }\end{array}$} & \multicolumn{2}{|c|}{ Cystoscopy biopsies } & \multirow{2}{*}{$\begin{array}{c}\text { Chi-square } \\
\text { test }\end{array}$} \\
\hline & \multirow{2}{*}{$\begin{array}{c}\text { Positive } \\
(\mathrm{n}=30)\end{array}$} & \multirow{2}{*}{$\begin{array}{c}\text { Negative } \\
(\mathrm{n}=10)\end{array}$} & \\
\hline & & & $\mathrm{x}^{2}$ \\
\hline
\end{tabular}

Mass present or absent:

- Absent

$\begin{array}{llllll}11 & 36.7 & 5 & 50.0 & 0.556 & 0.456\end{array}$

- Present

$\begin{array}{llll}19 & 63.3 & 5 & 50.0\end{array}$

Morphology:

- Irregular wal

$\begin{array}{llllll}10 & 33.3 & 3 & 30.0 & 0.137 & 0.934\end{array}$

thickening

- Polypoid

$\begin{array}{llll}13 & 43.3 & 5 & 50.0\end{array}$

- Sessile

$\begin{array}{llll}7 & 23.3 & 2 & 20.0\end{array}$

Location:

- Basal

$\begin{array}{llllll}6 & 20.0 & 3 & 30.0 & 0.610 & 0.894\end{array}$

- Dome

$\begin{array}{llll}11 & 36.7 & 3 & 30.0\end{array}$

- Lt lateral

$\begin{array}{llll}8 & 26.7 & 2 & 20.0\end{array}$

- Rt lateral

$\begin{array}{llll}5 & 16.7 & 2 & 20.0\end{array}$

Size $(\mathrm{mm})$ :

\begin{tabular}{lllllll}
$\bullet<5$ & 9 & 30.0 & 6 & 60.0 & 3.603 & 0.165 \\
$\bullet 6-10 \mathrm{~m}$ & 11 & 36.7 & 1 & 10.0 & & \\
$\bullet>10$ & 10 & 33.3 & 3 & 30.0 & & \\
\hline
\end{tabular}

Table (6): Feature of malignant masses by CT distribution of the study group $(n=30)$

\begin{tabular}{lll}
\hline & No. & $\%$ \\
\hline Bladder wall thickness: & & \\
$\quad$ Diffuse wall thickness & 4 & 13.3 \\
$\quad$ Focal wall thickness & 6 & 20.0 \\
Enhancement pattern: & & \\
$\quad$ Early & 14 & 46.7 \\
Late & 0 & 0.0 \\
Extravesical extension: & & \\
$\quad$ Positive & 11 & 36.7 \\
Negative & 19 & 63.3 \\
Lymph node shape: & & \\
Round & 6 & 20.0 \\
Oval & 0 & 0.0 \\
Lymph node hilum: & & \\
Fatty hilum & 0 & 0.0 \\
Low attenuation & 6 & 20.0 \\
Classification (n=40): & & \\
Malignant & 4 & 10.0 \\
Benign & 1 & 2.5 \\
Negative & 35 & 87.5 \\
\hline
\end{tabular}


This table shows that the Bladder wall thickness Diffuse wall thickness (13.3\%), focal wall thickness (20.0\%); enhancement pattern early $(0.0 \%)$, late (46.7\%); extravesical extension positive (36.7\%), negative $(63.3 \%)$; lymph node shape oval $(0.0 \%)$, round $(20.0 \%)$; lymph node hilum fatty hilum $(0.0 \%)$, low attenuation $(20.0 \%)$ and classification malignant $(10.0 \%)$, benign $(2.5 \%)$ and negative $(87.5 \%)$.

Table (7): Cystoscopy biopsies results distribution of the study group positive and negative.

\begin{tabular}{lcc}
\hline Cystoscopy biopsies & No. & $\%$ \\
\hline Negative & 10 & 25.0 \\
Positive & 30 & 75.0 \\
\hline
\end{tabular}

This table shows that $(75 \%)$ were positive for malignant cells and $(25 \%)$ were negative for malignant cells.

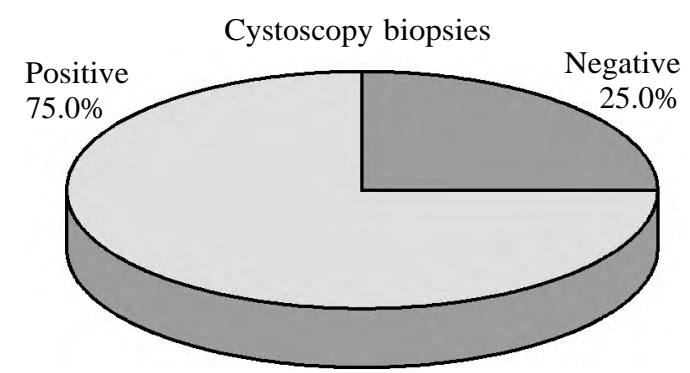

Fig. (5): Pie chart cystoscopy biopsies results distribution of the study group regarding malignant cells.

Table (8): Receiver-Operating Characteristic (ROC) curve for prediction of lesions using the $\mathrm{CT}$ results.

\begin{tabular}{lcccc}
\hline Sen. & Spe. & PPV & NPV & Accuracy \\
\hline $93.3 \%$ & $90.0 \%$ & $96.6 \%$ & $81.8 \%$ & $92.5 \%$ \\
\hline
\end{tabular}

CT results

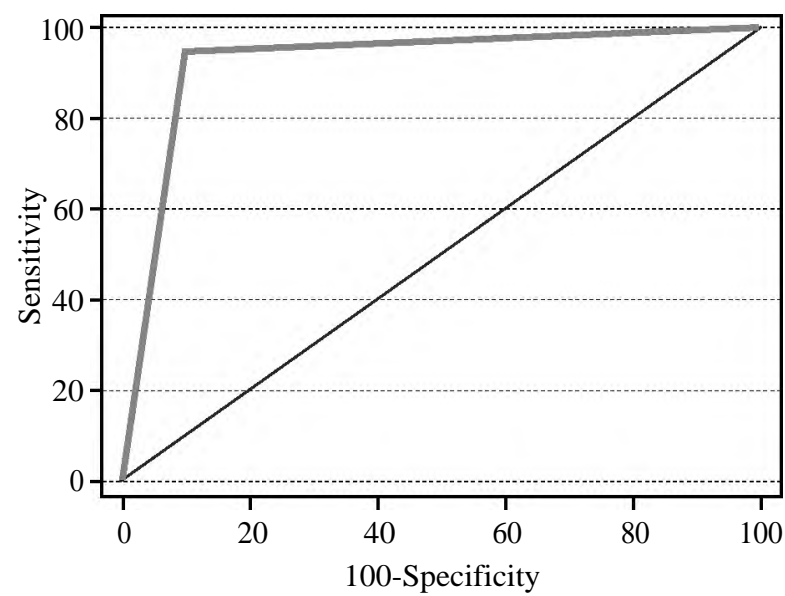

Fig. (6): Receiver-Operating Characteristic (ROC) curve for prediction of lesions using the CT results.
Receiver Operating Characteristics (ROC) curve show sensitivity (sen.) of $93.3 \%$ specificity (spe.) of $90 \%$ Positive Predictive Value (PPV) of $96.6 \%$, Negative Predictive Value (NPV) of $81.8 \%$ with diagnostic accuracy of $92.5 \%$.

\section{Illustrative cases:}
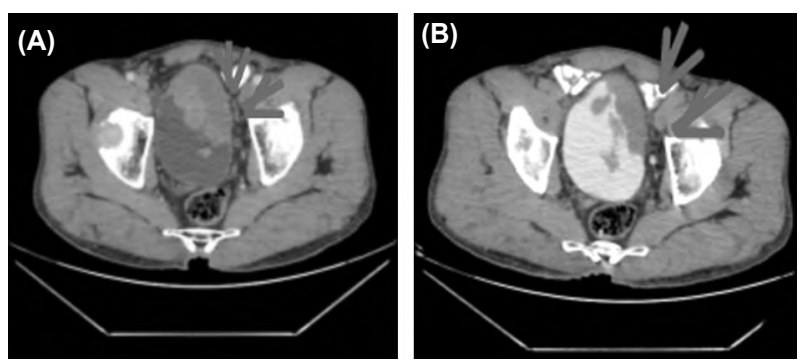

Fig. (7): 64 year patient presented with hematuria for 3 months duration, nocturia, and history of schistosomiasis infection, C.T. axial (A) Early (B) Late phase reveals a heterogeneously enhanced soft tissue mass lesion in the left anterior wall of the urinary bladder, the mass seen as a filling defect in the late phase with extravesical extension (as show in red arrows) and the cystoscopy biopsies reveal high grade transitional cell carcinoma (grade 4) with focal squamous differentiated and invasion of muscularis propria.

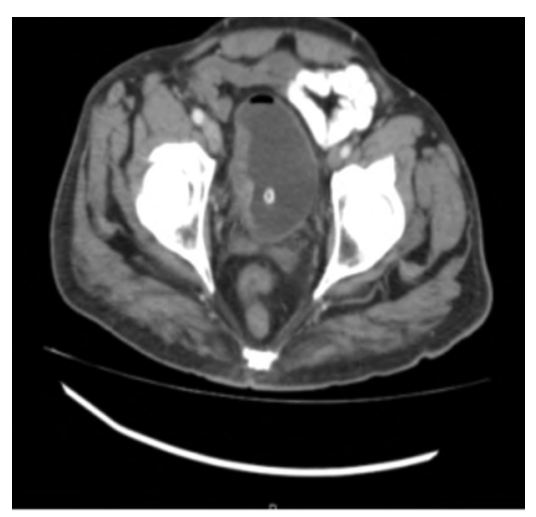

Fig. (8): 74 year old patient presented with frequency, abdominal pain, and intermittent attacks of hematuria axial C.T scan (early phase) shows right lateral urinary bladder wall irregular thickening with mass formation yet, cystoscopic finding reveal it to be of benign nature due to chronic cystitis.
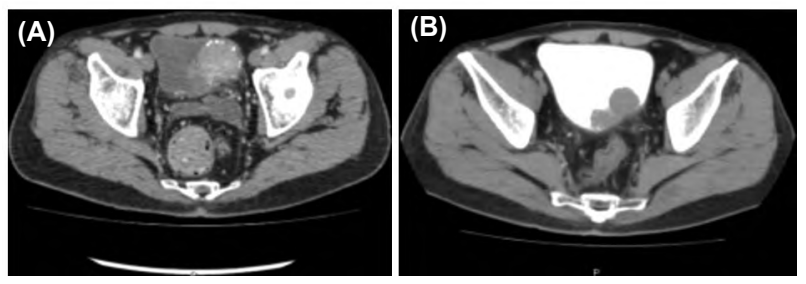

Fig. (9): 57 years old male patient presented with hematuria, frequency, and cachexia, C.T. axial cuts (A) Early (B) Late phase reveals heterogeneously enhancing fungating urinary bladder soft tissue mass arising mainly from the left lateral portion of the trigone, the mass inseparable from the upper portion of the prostate and mass seen as a filling defect in the late phase and Cystoscopy reveals low grade invasive papillary urothelial carcinoma. 


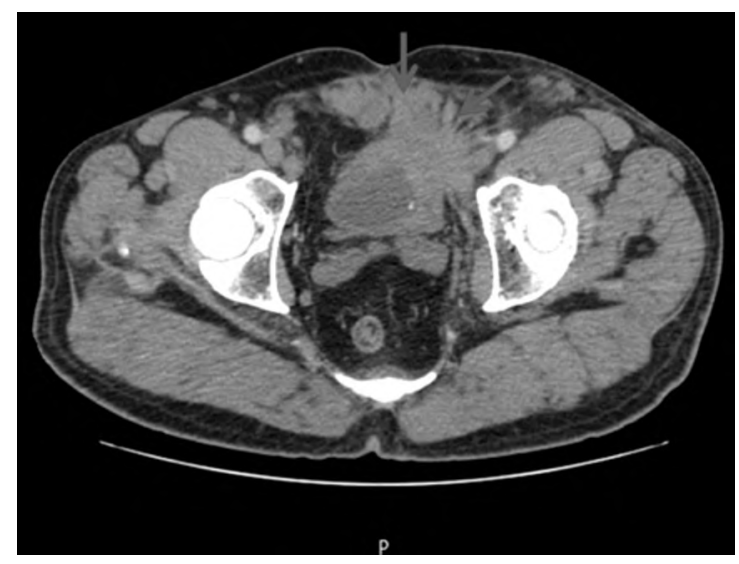

Fig. (10): 74 years old male presented with painless hematuria and urine retention for 1-month duration and C.T. axial cut early phase reveals an irregular heterogenous soft tissue lesion is arising from the left lateral urinary bladder wall with irregular thickening. This soft tissue lesion is seen fungating and extending beyond the perivesical space with invasion of the anterior abdominal wall (red arrows), Cystoscopy biopsies reveals squamous cell carcinoma low grade.

\section{Discussion}

Bladder carcinoma is the most common tumor among the lower urinary tract. Conventional cystoscopy plays a key role in diagnosis and local management of bladder carcinoma [12] . Conventional cystoscopy is the essential method for the detection and direct visualization of bladder cancer; however, it has many limitations: It is invasive, expensive, and time-consuming technique. Several complications may occur during a cystoscopy examination: Infections, bladder perforation, scarring and stricture of the urethra.

In recent years, $\mathrm{CT}$ technology has undergone rapid development, with improvement in diagnostic accuracy of bladder neoplasms [13]

Since its first use, CT cystography has demonstrated promising results for the diagnosis of bladder lesions, the introduction of 16-64 MDCT scanners significantly improved spatial resolution by the use of thinner slice thickness, collimation, and reconstruction increment, which enable fast execution and high resolution of the examination. Moreover, it allows acquisition of Multiplanar Reformatted Images (MPR) very similar to that of axial plane. Combined evaluation by CT cystography, MPR, and virtual images has been shown increase the effectiveness of the technique especially for the detection of small lesions [14].

In our study $11(27.5 \%)$ patients have positive DRE and PV which is consistent with study that revealed $(27.1 \%)$ of the sample have positive DRE.
In our study $29(72.5 \%)$ patients show malignant features on CT and $11(27.5 \%)$ patients do not reveal a malignancy feature. In the other hand our study show $30(75 \%)$ patients have a malignant cystoscopic biopsy and $10(25 \%)$ patients have a benign cystoscope biopsy Fig.(8), which is consistent with Reem H, Rmon [15] study that had a sample of 35 patients showed 34 (97\%) patients revealed a malignancy features and only 1 patient with malignancy features.

In our study mass $16(40 \%)$ of cases show irregular wall thickening on CT, with no definite mass lesion that were confirmed to be of malignant nature on cystoscopic biopy. Which is nearly similar result to Reem H, Rmon [15] as showed 28 (80\%) mass of the total 35 lesion and the miss diagnosis was due to nature of the lesion which is only wall thickening just like in our study, also similar result seen by the study of Jeong K, et al., [16] showing $27(67.5 \%)$ mass from the total 40 lesion and the remaining $13(32.5 \%)$ are missed diagnosed for the same previous cause.

In our study the $13(54.2 \%)$ patient has single lesion, $5(20.8 \%)$ patient has 2 lesions, 1 (4.2\%) patient has 4 lesions, and $5(20.8 \%)$ patient has 5 lesions, also our study show a morphological variance by CT as $13(32.5 \%)$ has irregular wall thickening, Fig. (8), 18 (45\%) patients has polypoidal lesion, and $9(22.5 \%)$ patients has sessile lesion; that is consistent with result of Reem $\mathrm{H}$, Rmon [15] showed 14 (50\%) has a single lesion, 4 (14\%) patient has 2 lesion and $2(7 \%)$ patient has 3 lesions in addition they showed $12(42 \%)$ polypoidal lesion, $14(50 \%)$ sessile lesion and 2 (7\%) irregular wall thickening.

In our study the $\mathrm{CT}$ shows lesions in different the location in bladder as $922.5 \%$ ) basal lesion location, 14 (35\%) dome lesion lacation, $10(25 \%)$ Lt lateral lesion location Figs. $(8,10)$ and $7(17.5 \%)$ Rt lateral lesion location Fig. (8). This is similar to the result of Mohammed F, Amr M [17] where 8 (33\%) basal, 8 (33\%) dome, 4 (16.6\%) Rt lateral, and $4(16.6 \%)$ Lt lateral. While Jeong K, et al., [16] showed there was 9 (60\%) dome, 5 (33\%) basal, and $1(6 \%)$ Lt lateral.

In our study the CT shows lesions of different size range divided into 3 categories 15 (37.5\%) lesion $<5 \mathrm{~mm}, 12(30 \%)$ lesion 6-10mm and 13 $(32.5 \%)$ lesions $>10 \mathrm{~mm}$ Figs. (7-10) this similar to the result of Masahiro J, et al., [18] that showed $12(20 \%)<5 \mathrm{~mm}, 17(29 \%) 6-10 \mathrm{~mm}$ and $30(51 \%)$ $>10 \mathrm{~mm}$, also [17] showed $1940 \%)<4 \mathrm{~mm}, 21(44 \%)$ 4-9mm, 7 (14\%) >9mm. 
In our study $4(13.3 \%)$ patients show diffuse wall thickness Fig. (10) and $6(20 \%)$ patients with focal wall thickness as a feature of malignancy on CT which is consistent with Wan song, et al., [19] showed $25(15 \%)$ patients with diffuse wall thickness and $20(11 \%)$ patient with focal wall thickness.

In our study 14 (46.7\%) masses show early enhancement pattern on CT scan that indicated malignancy features of masses on CT Figs. $(7,9,10)$ which is consistent with Xie Q, Zhang, et al., [20] showed $56(61 \%)$ masses with early enhancement pattern on CT scan.

In our study $11(36,7 \%)$ masses showed extravesical extension that indicated malignancy features of masses by CT Figs. $(7,10)$ while $19(63.3 \%)$ masses show no extravesical extension which consistent with Quek L, et al., [21] that showed 69 (29\%) masses with extravesical extension and 167 $(71 \%)$ masses with no extravesical extension.

In our study $6(20 \%)$ lymph nodes were round in shape and $6(20 \%)$ lymph node with low attenuated hilum that indicated malignancy features by CT which is consistent with Yong Li, Feiju Diao, Siya Shi [22] reported 5 (16\%) oval lymph nodes and $4(12 \%)$ lymph node with low attenuated hilum.

This Raman SP and Fishman EK showed 4 (10\%) masses with calcification revealed malignancy feature that confirmed by cystoscopy, 1 $(2.5 \%)$ mass with calcification revealed benignity nature confirmed by cystoscopic biopsy and 35 $(87.5 \%)$ masses with no calcification which is consistent with Raman SP and Fishman EK [23] reported $4(5 \%)$ masses with malignant calcification, $1(1.5 \%)$ mass with benign calcification and $70(93.5 \%)$ masses with no calcification.

In our study the CT detect 28 (70\%) malignant lesions that where confirmed by cystoscopic biopsy and 1 case misdiagnosed as a malignant lesion by $\mathrm{CT}$ and not revealed malignant by cystoscopic biopsy Fig. (8), 2 (5\%) lesions were misdiagnosed as a benign lesion on CT, yet, revealed to be malignant on cystoscopic biopsy and $9(22.5 \%)$ lesions were diagnosed as benign on CT and confirmed on cystoscopic biopsy.

Statistically significant difference is noted between positive and negative results of malignancy according to CT results with a $p$-value of $(<0.001)$; then the CT showing a sensitivity of $93.3 \%$, specificity of $90 \%$, positive predictive value of $96.6 \%$, negative predictive value of $81.8 \%$ with diagnostic accuracy of $92.5 \%$ in urinary bladder neoplastic masses detection, a similar result seen by Benjamin
W, et al., [24] CTU were compared with the histopathological findings, there was one false-positive and there was three false-negative diagnoses, indicating a sensitivity of 0.93 and a specificity of 0.99 , with a 0.98 positive and 0.97 negative predictive value for detecting bladder cancer, while (Christopher et al., 2011) showed that CT urography as replicant test for cystoscopy for diagnosing bladder cancer was with a sensitivity of $95 \%$, specificity of $83 \%$, positive predictive value of $58 \%$, negative predictive value of $98 \%$.

\section{Conclusion:}

Conventional Cystoscopy (CC) is remaining the gold standard for the evaluation of the urinary bladder, but MDCT urography is useful for examination of patients especially when the $\mathrm{CC}$ is contraindicated such as hemorrhage, perforation, difficult to doing it or unsatisfactory in interpretation, and as a complementary technique in the evaluation of areas difficult to evaluate with CC. Especially with the MDCT results satisfactory in finding lesions smaller than $5 \mathrm{~mm}$. MDCT urography give us an opportunity for early detection bladder tumors because its reliability and accuracy and our results support that.

\section{References}

1- WONG-YOU-CHEONG J., WOODWARD P., MANNING M. and SESTERHENN I.: Neoplasms of the Urinary Bladder: Radiologic-Pathologic Correlation. RadioGraphics, 26: 553-80, 2006.

2- DIGHE M.K., BHARGAVA P. and WRIGHT J.: Urinary bladder masses: Techniques, imaging spectrum, and staging. Journal of Computer Assisted Tomography, 35 (4): 411-24, 2011

3- AMIN M. and ABD EL HAMID A.: The diagnostic accuracy of multi-detector computed tomography with multiplanar reformatted imaging and virtual cystoscopy in the early detection and evaluation of bladder carcinoma: Comparison with conventional cystoscopy. Abdom Imaging, 38: 184-92, 2013.

4- FEDWA S.A., SOLIMAN A.S., ISMAIL K., HABLAS A., et al.: Incidence analyses of bladder cancer in Nile Delta Region of Egypt. Cancer Epidemiology, 33 (3-4): 176-81, 2009

5- GABR A. ELBADRY M., ELSHERIEF A. and TAWFIEK E.: Computed tomography-virtual cystoscopy in the evaluation of a bladder mass: Could it replace standard conventional cystoscopy? Arab Journal of Urology, 11: 36974, 2013.

6- CHA K., HADJIISKI L., CHAN H.P., COHAN R., et al.: Detection of urinary bladder mass in CT urography with SPAN. Med. Phys., 42 (7), 2015.

7- TEKES A., KAMEL I.R., CHAN T.Y., et al.: MR imaging features of non-transitional cell carcinoma of the urinary bladder with pathologic correlation. A.J.R. Am. J. Roentgenol., 180: 779-84, 2003. 
8- VERMA S., RAJESH A., PRASAD S.R., et al.: Urinary bladder cancer: Role of MR imaging. Radiographics, 32 (2): 371-87, 2012.

9- KARABACAK O.R., CAKMAKCI E., OZTURK U., et al.: Virtual cystoscopy: The evaluation of bladder lesions with computed tomographic virtual cystoscopy. Can. Urol. Assoc. J., 5 (1): 34-47, 2011.

10- SFETSAS K. and MITROPOULOS D.: Reducing understaging of bladder cancer with the aid of photodynamic cystoscopy. Journal of the Egyptian National Cancer Institute, 28: 89-94, 2016.

11- KIM J.C.: CT features of bladder small cell carcinoma. Clin. Imaging, 28: 201, 2004

12- KAWAY N., MIMURA T., NAGATA D., et al.: Intravenous urography-virtual cystoscopy is a better preliminary examination thanair virtual cystoscopy, BJU Int., 94: 382 6, 2004.

13- THALI-SCHAWB C.M., WOODWARD P.J. and WAGNER B.J.: Computedtomographic appearance of urachal adenocarcinomas: Review of 25 cases. Eur. Radiol., 15: 79-84, 2005.

14- TSAMPOULAS C., TSILI A.C., GIANNAKIS D., et al.: 16-MDCTCystoscopy in the evaluation of neoplasms of the urinary bladder. A.J.R. Am. J. Roentgenol., 190: 72935, 2008.

15-REEM H. and REMON Z.: Bladder tumors after Recurrent transurethral resection: Diagnostic yield of MDCT-virtual cystoscopy. The Egyptian Journal of Radiology and $\mathrm{Nu}-$ clear Medicine, 48: 509-17, 2017.

16- JEONG K., SOO-YOUN P., HO SUNG K., et al.: Comparison ofVirtualCystoscopy, Multiplanar Reformation, and Source CT Images with Contrast Material-Filled Bladder for Detecting Lesions. A.J.R., 185: 689-96, 2005
17- MOHAMMED F. and AMR M.: The diagnostic accuracy of multidetector computed tomography with multiplanar reformatted imaging and virtual cystoscopy in the early detection and evaluation of bladder carcinoma: Comparison with conventional cystoscopy. Egypt Abdom. Imaging, 38: 184-92, 2013.

18- MASAHIRO J., AKIHIRO T., HIROSHI S., et al.: Detection of Bladder Tumors with Dynamic Contrast-Enhanced MDCT. AJR, 188: 913-8, 2007.

19- WAN SONG, JEON H.G., JEONG B.C., et al.: Clinica significace of incidentally detected bladder wall thickening on computed tomography. Int. Urol. Nephrol., 201749: 191-6.

20- XIE Q., ZHANG J., P.H. WU, et al.: Bladder transitional cell carcinoma correlation of contrast enhancement on computed tomography with histological grade and tumour angiogenesis, 60: 215-23, 2005.

21- QUEK L., JOHN P., PETER, et al.: Nature history of surgically treated bladder carcinoma with extravesical tumor extension. American Cancer Society, 98: 865-978, 2004.

22- YONG LI, FEIJU DIAO and SIYA SHI: Computed tomography and magnetic resonance imaging evaluation of pelvic lymph node metastasis in bladder cancer. Chinese Journal of Cancer, 37: 2523-48, 2018.

23- RAMAN S.P. and FISHMAN E.K.: Bladder Malignancies on CT: The Underrated Role of CT in Diagnosis. American Journal of Roentgenology, 203: 347-54, 2014

24- BENJAMIN W., TURNE Y., JONATHAN M.G., et al.: Computed tomography urography for diagnosingbladder cancer. Departments of Urology and Radiology, 98: 3458, 2006.

\section{مظاهر آورام المثانة البولية بواسطة الآثعة المقطعية متعددة المقاطع}

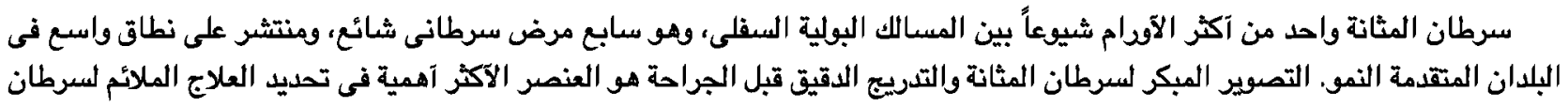

المثانة.

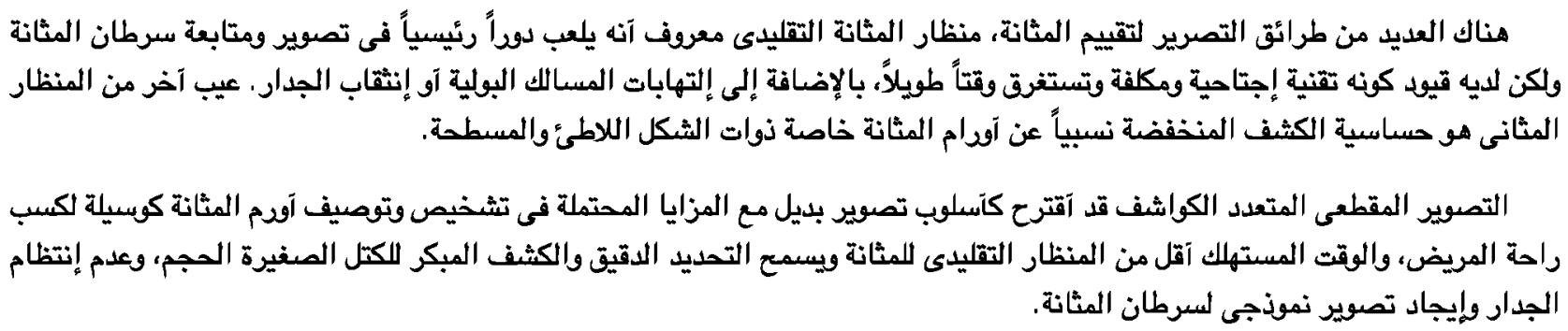

